\title{
Vascular epiphytes contribute disproportionately to global centres of plant diversity
}

\author{
Amanda Taylor ${ }^{1}$ (D) | Gerhard Zotz ${ }^{2,3}$ (D) | Patrick Weigelt ${ }^{1}$ (D) | Lirong Cai ${ }^{1}$ (D) | \\ Dirk Nikolaus Karger $^{4}$ (D) | Christian König ${ }^{5}$ (D) | Holger Kreft ${ }^{1,6}$ (D)
}

${ }^{1}$ Biodiversity, Macroecology \& Biogeography, Faculty for Forest Sciences \& Forest Ecology, University of Göttingen, Göttingen, Germany

${ }^{2}$ Institute of Biology and Environmental Sciences, Carl von Ossietzky University of Oldenburg, Oldenburg, Germany

${ }^{3}$ Smithsonian Tropical Research Institute, Panama, Republic of Panama

${ }^{4}$ Swiss Federal Research Institute WSL, Birmensdorf, Switzerland

${ }^{5}$ Ecology and Macroecology group, Institute for Biochemistry and Biology, University of Potsdam, Potsdam, Germany

${ }^{6}$ Centre of Biodiversity and Sustainable Land Use (CBL), University of Göttingen, Göttingen, Germany

\section{Correspondence}

Amanda Taylor, Biodiversity, Macroecology $\&$ Biogeography, Faculty for Forest Sciences \& Forest Ecology, University of Göttingen, Büsgenweg 1, 37077 Göttingen, Germany. Email: amanda.taylor@uni-goettingen.de

\section{Funding information}

Swiss Data Science Project; Swiss National Foundation, Grant/Award Number: 20BD21_184131; Swiss Federal Institute for Forest, Snow and Landscape Research, Grant/Award Number: ClimEx, FeedBaCks and exCHELSA; Deutsche Forschungsgemeinschaft, Grant/Award Number: 447332176, DynaCom and ZU 361-1/1

Editor: Renske E. Onstein

\begin{abstract}
Aim: Vascular epiphytes are ubiquitous components of wet tropical forests where they contribute substantially to local and regional plant diversity. While some basic epiphyte distribution patterns are relatively well studied, little effort has been made to understand the drivers responsible for constraining their global distribution. This study quantifies the substantial contribution of epiphytes to global gradients and centres of vascular plant diversity and explores whether epiphytes vary from terrestrial plants in relation to contemporary and historical environmental variables.

Location: Global.
\end{abstract}

Time period: Present.

Major taxa studied: Tracheophyta.

Methods: Using a comprehensive epiphyte species list (EpiList 1.0), and distribution information for 27,850 epiphyte species derived from numerous literature sources, we describe the global biogeography of epiphytes. We use generalized linear mixed effects models to assess the relationship between epiphytic and terrestrial plant diversity, and contemporary and historical environmental predictors.

Results: Epiphytes substantially contribute to global centres of vascular plant diversity, accounting for up to $39 \%$ of the vascular flora in Neotropical regions. Epiphytes decrease in species numbers with increasing latitude at a rate three times faster than terrestrial plants, a trend that is driven mainly by the distribution of tropical forests and precipitation. Further, large regional differences emerge that are explained by several large endemic angiosperm families (e.g., Neotropical Bromeliaceae) that are absent in other tropical regions.

Main conclusions: Our results show that epiphytes are disproportionately diverse in most global centres of plant diversity and play an important role in driving the global latitudinal diversity gradient for plants. The distribution of precipitation and tropical forest area emerge as major drivers of the latitudinal diversity gradient in epiphyte species richness. Finally, our findings demonstrate how epiphyte floras in different biogeographical realms are composed of different families and higher taxa, revealing an important signature of historical biogeography. 


\section{KEYWORDS}

epiphytes, latitudinal diversity gradient, Neotropics, Orchidaceae, pteridophytes, tropical

forest

\section{1 | INTRODUCTION}

Epiphytic vascular plants-defined as non-parasitic, vascular plants that germinate and are permanently structurally dependent on other plants-are one of the most prominent life-forms in tropical forest canopies (Zotz, 2013, hereafter referred to as 'epiphytes'). In humid tropical forests, epiphytes may locally account for up to $50 \%$ of the vascular flora (Kelly et al., 2004), while globally they constitute roughly $10 \%$ of the world's higher plant biodiversity (Zotz, Weigelt et al., 2021). Where they reach higher abundances, epiphytes play a critical role in forest nutrient and water cycling (Gotsch et al., 2016), and can contribute substantially to local plant biomass (Díaz et al., 2010; Nadkarni et al., 2004; Zotz, 2016). Moreover, epiphytes provide crucial habitat for canopy-dwelling fauna (Méndez-Castro et al., 2018; Stuntz et al., 2002), while also adding to the structural complexity of forest canopies (Zotz, 2016).

Some basic regional and global patterns in epiphyte richness are well established: epiphytes reach their greatest numbers in the tropics and decrease in numbers towards the poles (Benzing, 1990; Gentry \& Dodson, 1987; Madison, 1977; Zotz, 2016), epiphyte richness is lower in the Northern relative to the Southern Hemisphere (Burns, 2010; Dawson, 1986; Gentry \& Dodson, 1987; Zotz, 2005), and distribution patterns of epiphytic pteridophytes differ from those of epiphytic seed plants (Madison, 1977; see review by Zotz, 2016). Despite this, no study has explored such patterns quantitatively and at a global scale for over 30 years (Gentry \& Dodson, 1987), and little progress has been made to understand the mechanisms responsible for constraining the global distribution of epiphytes. Since the last global assessment, the advancement of molecular phylogenetic techniques and the development of key spatial databases have considerably improved both plant taxonomic classification and our knowledge of plant distributions, including epiphytes (Zotz, Weigelt et al., 2021). Now it is possible to fully grasp the global extent of vascular epiphyte distributions, addressing questions on how epiphytes contribute to overall vascular plant diversity or whether their responses to environmental gradients differ compared to terrestrial plants.

Recent studies have illustrated striking differences in epiphyte diversity patterns compared to terrestrial representatives from certain groups (e.g., pteridophytes, Nervo et al., 2016; orchids, Taylor et al., 2021), which suggests that epiphytic and terrestrial plants indeed vary in their responses to environmental gradients. Epiphytes are expected to be more tightly coupled to atmospheric conditions than terrestrial plants due to their aerial growth habit and limited access to water, which strongly influences the vertical partitioning of epiphytes within the canopy (Mendieta-Leiva et al., 2020). Evidence for water availability being typically the most important limiting factor for epiphytes is provided by the frequent occurrence of traits among different epiphytic lineages related to water capture, storage, and use-efficiency, such as water-impounding tanks (Zotz et al., 2020), fleshy leaves, succulent stems (including pseudobulbs, Göbel et al., 2020), crassulacean acid metabolism (CAM) photosynthesis (Benzing, 1987), or aerial roots that aid in capturing and storing water (Pridgeon, 1987).

Epiphytism has evolved independently multiple times among vascular plants, and the evolution of epiphytism-associated traits is thought to have prompted the rapid and independent diversification observed in some plant families, such as the Orchidaceae (75\% epiphytic, Givnish et al., 2015; Silvera et al., 2009; Zotz, Weigelt et al., 2021), Bromeliaceae (59\% epiphytic, Givnish et al., 2011; Zotz, Weigelt et al., 2021), and leptosporangiate ferns (e.g., Polypodiaceae $89 \%$ epiphytic, Hymenophyllaceae $72 \%$ epiphytic, Schuettpelz \& Pryer, 2009; Zotz, Weigelt et al., 2021). Still, epiphytism is highly unevenly distributed throughout the plant kingdom, being prevalent in some clades, and surprisingly underrepresented (e.g., Asteraceae, Poaceae, $<0.1 \%$ epiphytic, gymnosperms $<0.2 \%$, Zotz, Weigelt et al., 2021) or absent from others (e.g., Brassicaceae, Euphorbiaceae, Fabaceae). The uneven representation of epiphytes among clades also emerges geographically. For instance, while there is a relatively uniform representation of epiphytic families across all tropical realms, there is a considerable disparity in the number of species (Gentry \& Dodson, 1987). Why epiphytism evolved in a similar number of plant families in different regions, yet only diversified in some regions is not fully understood, although numerous hypotheses have been proposed (Table 1).

One possible explanation for the poorer representation of epiphytes outside of the tropics is that most epiphytic lineages evolved under warm, humid and non-seasonal conditions (Benzing, 1989) and the evolution of novel functional strategies to withstand a desiccating environment have remained relatively constant through time (i.e., niche conservatism, Wiens et al., 2010). Specifically, functional traits required to persist in very cold or highly seasonal climates (e.g., geophytic habit, annual life cycle) are not compatible with the epiphytic life-form, making it difficult for individuals to survive outside of tropical habitats (Hernández-Rojas et al., 2021; but see Gamisch et al., 2021). Given that most epiphytic lineages evolved in tropical forests, and all epiphytes require a host tree to grow on, the distribution of past and present tropical forests should also influence epiphyte richness patterns (Dawson \& Sneddon, 1969; Gentry \& Dodson, 1987; Madison, 1977; Table 1). For example, the reduction of tropical forest area during glacial periods could exacerbate the already strong dispersal limitations observed in epiphyte metacommunities (Einzmann et al., 2021). Thus, past conditions can leave a legacy in contemporary diversity patterns and should be considered to fully capture the global distribution of epiphytes. 
TABLE 1 Summary of observed global patterns in epiphyte richness and associated hypotheses, references, and potential predictors

\begin{tabular}{|c|c|}
\hline Global patterns & Main hypotheses \\
\hline $\begin{array}{l}\text { Prominent tropical } \\
\text { distribution }\end{array}$ & $\begin{array}{l}\text { Intolerance to low temperatures; } \\
\text { increased water scarcity at higher } \\
\text { latitudes; shorter dry seasons in } \\
\text { the tropics; refugia during the Last } \\
\text { Glacial Maximum (LGM). }\end{array}$ \\
\hline
\end{tabular}

Selected references
Schimper (1888), Benzing (1990),
Zotz (2005), Schimper
et al. (1903)

Potential predictors

Number of frost days, temperature, temperature seasonality, temperature of growing season, precipitation, precipitation seasonality, aridity, length of growing season, precipitation of growing season, current tropical forest area, historical tropical forest area (during the LGM and mid Miocene climate optimum, MCO), historical ice cover (during the LGM).

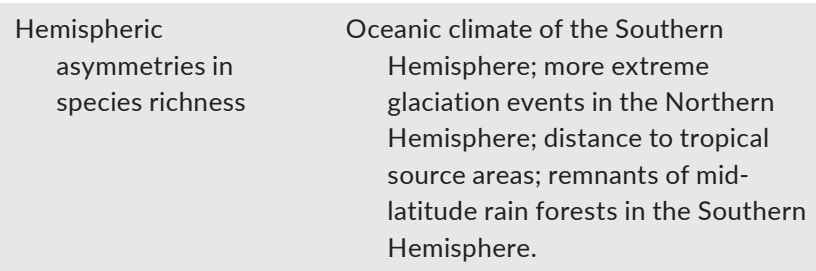

Oceanic climate of the Southern Hemisphere; more extreme glaciation events in the Northern Hemisphere; distance to tropical source areas; remnants of midlatitude rain forests in the Southern Hemisphere.

Miocene diversification/extinctions; Pleistocene extinctions; distribution of cloud forests.
Dawson (1986), Gentry and Dodson (1987), Benzing (1990), Zotz (2005)
Number of frost days, temperature, temperature seasonality, temperature of growing season, precipitation, precipitation seasonality, aridity, length of growing season, precipitation of growing season, current tropical forest area, historical tropical forest area, historical ice cover, realm.
Madison (1977), Gentry and Dodson (1987)
Precipitation, current tropical forest area, distribution of cloud forests, historical tropical forest area, historical climate (precipitation and temperature during the LGM), realm, area.

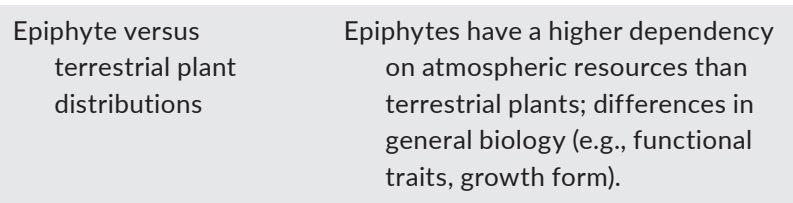

\section{Epiphytes have a higher dependency} on atmospheric resources than terrestrial plants; differences in general biology (e.g., functional traits, growth form).

\section{Gentry and Dodson (1987), Nervo et al. (2016), Taylor et al. (2021), Benzing (1998)}

Number of frost days, temperature, temperature seasonality, precipitation, precipitation seasonality, current tropical forest area, distribution of cloud forests, historical tropical forest area, historical ice cover, elevation.

\footnotetext{
Epiphytic pteridophyte versus seed plant distributions
}

\author{
Madison (1977), Zotz (2016), Kreft \\ et al. (2010)
}

Temperature, temperature seasonality, precipitation, precipitation seasonality, aridity, current tropical forest area, realm, area, elevation.
Here, we present the most detailed and quantitative assessment of the global distribution of epiphytes to date, which aims at disentangling spatial patterns of epiphyte richness and their contribution to global centres of plant diversity. We integrate a comprehensive epiphyte list (EpiList 1.0, Zotz, Weigelt et al., 2021) with distribution information for 27,850 epiphyte species obtained from three major plant distribution databases, including the Global Inventory of Floras and Traits database (GIFT, Weigelt et al., 2020), World Ferns (Hassler, 2021), and the World Checklist of Selected Plant Families (WCSP, 2018), as well as numerous individual species-level accounts from the literature (all data references can be found in Supporting
Information Appendix S1). First, we present a global map of epiphyte species richness, highlighting the relative contribution of different families to continental and global patterns of epiphyte diversity. Second, we re-evaluate prominent hypotheses that have been proposed to explain epiphyte distribution patterns (Table 1), including both historical, for example, past distributions of forest biomes, glaciation events, past climatic conditions (Dawson, 1986; Gentry \& Dodson, 1987; Zotz, 2005), and contemporary drivers, for example, current distribution of forest biomes, current climatic conditions, elevational range (Kreft et al., 2004; Krömer et al., 2005). Lastly, we compare patterns of epiphyte richness to terrestrial plant richness 
and establish whether they differ in their responses to environmental conditions.

\section{2 | METHODS}

\section{1 | Epiphyte and terrestrial plant distribution data}

As a baseline list of all known epiphyte species, we used the EpiList 1.0 database, which contains over 31,000 epiphyte and hemiepiphyte species names collated from 978 literature sources (Zotz, Weigelt et al., 2021). We included in our analyses all obligate epiphytes and hemiepiphytes, defining hemiepiphytes as plants that germinate in tree crowns (as epiphytes) but unlike true epiphytes grow roots that eventually make contact with the forest floor (Zotz, Almeda et al., 2021). We justify including hemiepiphytes as they begin life as epiphytes and are thus under the same constraints during the most vulnerable life stage. Species names were standardized according to the World Flora Online taxonomic backbone (WFO, 2019) for seed plants, and the World Ferns database (Hassler, 2021) for ferns and lycophytes (hereafter pteridophytes). To gain complete, global coverage of epiphyte distributions we derived distribution data from a variety of literature and database sources. All pteridophyte species distributions were obtained from the World Ferns database (Hassler, 2021), while seed plant distributions were mainly derived from the Global Inventory of Floras and Traits database (GIFT, Weigelt et al., 2020), and the World Checklist of Selected Plant Families (WCSP, 2018). External literature searches were performed for individual species that could not be matched to any database (all data references can be found in Supporting Information Appendix S1).

To obtain a continuous global scheme of regional epiphyte compositions, we aggregated the number of epiphyte species following the Taxonomic Database Working Group (TDWG) classification of botanical countries. The TDWG scheme defines botanical countries as standardized geographical boundaries independent of political configurations (Brummit, 2001). Some TDWG regions do not have complete species lists (e.g., 'Chile South'), although complete lists were available for the smaller, nested regions within. Thus, in cases where complete checklists were available for all smaller regions nested inside a larger TDWG region, we aggregated these (e.g., Chile South = Región de los Lagos, Aisén del General Carlos Ibáñez del Campo, Región de Magallanes y de la Antártica Chilena). While we aimed to have complete global coverage of all epiphyte species distributions, some TDWG regions may only be partially covered due to incomplete checklists, or because checklists only represented certain plant families or nested regions. Thus, we assessed data completeness in two different ways: (a) region completeness, and (b) family distribution completeness. In the case of region completeness, we assigned a ' 1 ' to regions in which we are confident that the region checklist is complete or near complete, and a ' 0 ' to regions that are only partially complete. With these criteria, we obtained confident checklists for $75 \%$ and $84 \%$ of regions for seed plants and pteridophytes, respectively. To further assess the completeness of seed plant distributions, we compiled families listed in the WCSP with completed reviews (https://wcsp.scien ce.kew.org/compilersReviewers.do), totalling $47 \%$ of all seed plant families in our study. However, as these completed reviews cover several large epiphyte families such as Araceae, Bromeliaceae and Orchidaceae, the proportion of epiphytic seed plants with complete distribution information amounted to $87 \%$ and $78 \%$ with the inclusion of pteridophytes. Our final dataset consisted of 76,427 species distribution records for 27,850 epiphyte species in 273 regions (including continental island and mainland regions). Although oceanic islands can have diverse epiphyte floras $(3,608$ species from this study), we excluded them because isolation and island ontogeny significantly influence plant assembly and richness patterns (Whittaker et al., 2008).

To compare epiphyte and terrestrial plant distributions, we subtracted the total number of epiphytes per botanical country from the total number of vascular plants to obtain the total number of terrestrial species per botanical country and the proportional representation of epiphytes (hereafter 'epiphyte quotient', sensu Hosokawa, 1950). The same procedure was completed for two subsets-pteridophytes and seed plants-which required selecting botanical countries with complete pteridophyte (derived from Hassler, 2021), seed plant, and total richness values (derived from GIFT). Thus, our subset for the epiphyte quotient analysis was smaller, including a total of 267 regions for pteridophytes, 195 for seed plants and 196 for the total number of epiphytes (regions for which complete terrestrial checklists were available can be viewed in Supporting Information Figure S1).

We corrected for differences in area size among regions by standardizing species richness estimates per region to $10,000 \mathrm{~km}^{2}$ following Kier et al. (2005). We did this by first deriving empirically the slope ( $z$ value) of the global epiphyte species-area relationship assuming the well-supported power law model, which was then incorporated into a modified species-area equation:

$$
S_{e}=S_{u}\left(\frac{A_{e}}{A_{u}}\right)^{z}
$$

where $S_{e}$ is the area-corrected species richness of a region, $S_{u}$ is the region's observed species richness, $A_{e}$ is the constant area of $10,000 \mathrm{~km}^{2}, A_{u}$ is the observed area of a region in $\mathrm{km}^{2}$, and $z$ is the slope of the species-area relationship in log-log space (for $z$ values see Supporting Information Table S1). We accounted for geographical variation in species-area relationships by estimating separate slopes for each biome (Gerstner et al., 2014). For each region, the most dominant biome (in terms of area occupied) was assigned based on the biome scheme by Dinerstein et al. (2017). Greenland and Aruba were omitted due to being the sole regions with dominant 'rock and ice' and 'mangrove' biomes, respectively. Area corrections were only applied for mapping and comparisons of epiphyte richness among regions, while true, uncorrected species richness values were used in all models. 


\section{2 | Environmental predictor variables}

We related epiphyte richness to 10 contemporary and past environmental variables out of 19 variables that were initially considered. Variables included three contemporary climatic variables derived from CHELSA v1.2 (Climatologies at high resolution for the earth's land surface areas, Karger et al., 2017)-mean annual precipitation ( $\mathrm{mm}$, hereafter precipitation), precipitation seasonality (coefficient of variation in precipitation) and mean daily minimum temperature $\left({ }^{\circ} \mathrm{C}\right.$, hereafter temperature), all of which have been previously hypothesized or shown at regional to global scales to be important predictors of both epiphytic and terrestrial plant species richness (Gentry \& Dodson, 1987; Kreft \& Jetz, 2007; Taylor et al., 2021; Zotz, 2005). As a measure of habitat availability for epiphytes, we included the contemporary extent of tropical forest biomes $\left(\mathrm{km}^{2}\right)$. Contemporary tropical forest biomes were extracted from a global map of terrestrial biomes (Olson et al., 2001), and overlaid with our botanical country polygons to quantify the total area of tropical forest for each botanical country. In addition, we selected area $\left(\mathrm{km}^{2}\right.$, Weigelt et al., 2020) and elevational range ( $\mathrm{m}$, from the Global Multi-resolution Terrain Elevation dataset by Danielson $\&$ Gesch, 2011), which are important geographical predictors of species diversity. All environmental variables excluding the extent of tropical forest biomes and area were derived and averaged from raster layers at a resolution of 30 arc-seconds across each TDWG region.

We further considered three historical factors, reflecting past climate-Last Glacial Maximum (LGM) ice cover ( $\mathrm{km}^{2}$, Ehlers et al., 2011), and past distribution of tropical forests-LGM tropical forest area $\left(\mathrm{km}^{2}\right.$, Ray \& Adams, 2001) and tropical forest area during the Mid-Miocene climate optimum $\left(\mathrm{km}^{2}\right.$, Henrot et al., 2010). The extent of both historical tropical forest biomes was quantified in the same manner as for the distribution of contemporary tropical forested biomes. However, because biome definitions differed between datasets, we first standardized all biomes to match across datasets, delineating 'tropical rain forest', 'sub-tropical forest', and 'tropical seasonal forest' as 'tropical forest'. Finally, we explore continental differences in epiphyte occurrences, which allows inferences about idiosyncratic historical biogeographical patterns not captured by the environmental predictors (variable biogeographical realm). Like the classification of biomes, each region was assigned its respective realm following Olson et al. (2001) to explore the richness and relative contribution of different epiphyte families among the different continents. All data used for this analysis can be found in the Dryad depository at https:/doi.org/10.5061/dryad.kwh70rz46.

We also considered the number of frost days, length of growing season, precipitation of growing season, mean temperature of growing season, temperature seasonality, aridity, distribution of cloud forests, LGM precipitation, and LGM temperature. These variables were not included in the final analyses due to being highly correlated with other variables (at the threshold of $r \geq .70$ ), and for showing weaker relationships (lower correlation $r$ values) with epiphyte species richness compared to the retained uncorrelated variables (Dormann et al., 2013). For example, the number of frost days was highly correlated with temperature $(r=.86)$, and we retained temperature due to its stronger relationship with epiphyte species richness $(r=.61)$ compared to the number of frost days and epiphyte richness $(r=-.41)$.

\section{3 | Statistical analyses}

Generalized linear mixed effects models (GLMMs) with a Poisson and binomial error distribution (for proportion data) were implemented to analyse the effects of different environmental drivers on epiphyte and terrestrial plant richness and proportional representation, respectively. We chose GLMMs to overcome overdispersion, which we accounted for by including an observational-level random effect. We fitted separate GLMMs for seed plants and pteridophytes. We also fitted separate GLMMs with the single inclusion of realm to simply compare variation in epiphyte richness and quotient across continents without controlling for any environmental drivers. Likewise, we fitted separate GLMMs excluding Madagascar due to this continental island's unique evolutionary history, which might influence epiphyte diversity patterns for the Afrotropical realm. As we found no statistical difference, we present our results with the inclusion of Madagascar. All predictor variables except for temperature were $\log 10(x+1)$ transformed to reduce skewness. Moreover, to make the results comparable across different models, we scaled all predictor variables to zero mean and unit variance. Minimum adequate models were selected based on the corrected Akaike information criterion (AICc). We considered models with a $\triangle \mathrm{AICc}$ value $<2.0$ compared to the minimum AICc value to be the best-supported models following Burnham and Anderson (2004). Model residuals showed a low degree of spatial autocorrelation (e.g., total epiphyte richness: Moran's $I=.08, p \leq .01$ ). Including a spatial residual autocovariate (RAC) further reduced (Dormann et al., 2007) spatial autocorrelation (e.g., total epiphyte richness: Moran's $I=.03, p=.06$ ). However, because we found that accounting for spatial autocorrelation did not qualitatively alter our results, we opted to present the non-spatial models.

Quasi-Poisson and binomial generalized linear models were used to assess the simple relationship between epiphyte and terrestrial plant richness, proportional representation, and absolute latitude. For all proportion models, we did not consider regions with fewer than three plant species to reduce distortion of global patterns. Lastly, we regressed our epiphyte richness model residuals with absolute latitude to confirm that we captured all possible combinations of factors explaining variation in epiphyte richness with increasing latitude. All statistical analyses were conducted in the R environment (version 4.0.0, R Core Team, 2020) using the packages jtools (Long, 2019), Ime4 (Bates et al., 2015), MuMIn (Barton, 2020) and spdep (Bivand \& Wong, 2018). 


\section{3 | RESULTS}

\subsection{The contribution of epiphytes to global vascular plant diversity}

Barring Mediterranean climates, epiphytes substantially contribute to global centres of vascular plant diversity, accounting for $39 \%$ of the flora of Ecuador (excluding Galapagos), and $20 \%-26 \%$ of the floras of Panama, Brazil South, Costa Rica, Colombia, New Guinea and Sulawesi. Similarly, we find marked differences in epiphyte richness patterns, with area-corrected epiphyte richness being most impressive in the Neotropics, particularly in Ecuador (1,699 species per $10,000 \mathrm{~km}^{2} ; 5,574$ unstandardized total species richness), Costa Rica $(1,454 ; 2,660)$, Panama (1,192; 2,513) and Colombia (958; 5,520). On the contrary, epiphytes are under-represented in regions with large deserts (e.g., Egypt) or frequent freezing temperatures (e.g., Central European Russia, Figure 1, Supporting Information Figure S1).

As well as contributing to global centres of vascular plant diversity, epiphytes also play an important role in driving the latitudinal diversity gradient (Figure 2). Specifically, epiphytes decrease in species numbers with increasing absolute latitude at a rate three times faster than terrestrial plants (E slope: $-1.50 \pm 0.14$; $T$ slope: $-0.43 \pm 0.05 ; p \leq .01$, Supporting Information Figure S2), following a similar trend to the epiphyte quotient, which also decreases with increasing absolute latitude (EQ: $-1.33 \pm 0.14, p \leq .01$, Figure $2 a$ ). We also note a pronounced latitudinal asymmetry in which epiphyte richness and quotient decrease from the tropics to higher latitudes almost twice as rapidly in the Northern relative to the Southern Hemisphere. This relationship is stronger for epiphytic seed plants (north slope: $-1.52 \pm 0.01$; south slope: $-0.93 \pm 0.01 ; p \leq .01$ ) than for pteridophytes (north slope: $-0.92 \pm 0.02$; south slope: $-0.22 \pm 0.02 ; p \leq .01$ ), whose distributions extend further into temperate regions (Figure $2 b, c$ ).

Unsurprisingly, the Neotropics emerge as the most diverse biogeographical realm, with 51 out of 68 epiphytic plant families represented (Figure 3 ), including $63 \%$ of all epiphytes in our study $(17,433$ epiphyte species, uncorrected for area), and 3.5 times more species than the second most diverse realm (Indomalayan-4,984 species; $18 \%$ of all epiphytes). We find this pattern to be robust even when controlling for differences in area, climate and other variables among regions (Figure 4). Conversely, the Afrotropics is the least diverse tropical realm (1,714 species; 6\%), containing fewer species than Australasia $(4,602 ; 17 \%)$, with a notable absence or poor representation of several large angiosperm families, including Bromeliaceae $(0$ species), Ericaceae (0 species), Araceae (1 species) and Gesneriaceae (6 species), which form important components of the epiphyte flora in other tropical realms. Despite the Afrotropics having fewer species than Australia, no statistical difference was observed between the two realms when controlling for environmental variation among regions (Supporting Information Figure S3). Similarly, while the Indomalayan realm has significantly more epiphytes than the Afrotropics (Supporting Information Figure S3), this pattern does not hold when statistically controlling for environmental variation (Figure 4). The two largely temperate realms, the Palaearctic and
Nearctic, have the least diverse epiphyte floras, totalling 1,219 (4\%) and $786(3 \%)$ species, respectively. This pattern also holds when controlling for environmental factors, with the Palaearctic and Nearctic having significantly fewer epiphytes, particularly among seed plants, compared to all other biogeographical realms in our study.

Low epiphyte richness does not imply a low epiphyte quotient. To the contrary, the Afrotropics with the lowest epiphyte richness (of tropical realms) has some of the highest proportions of epiphytic pteridophytes, particularly in Gabon, Malawi and Mozambique, where $38 \%-43 \%$ of all pteridophytes are recorded as growing epiphytically. Orchidaceae are the most diverse plant family in all biogeographical realms, ranging in proportional representation from $40 \%$ (Nearctic, due to Mexico) to $77 \%$ (Australasia) with Polypodiaceae being a distant second (3\%-16\%). However, we also observe differences in the contribution of epiphyte families among the biogeographical realms. For example, almost entirely endemic to the New World, Bromeliaceae contribute significantly to epiphyte diversity in the Neotropics (11\%) and Nearctic (17\%), second only to the Orchidaceae. Likewise, Ericaceae form an important component of the Palaearctic epiphyte flora (8\%) and Apocynaceae and Gesneriaceae are diverse in the Indomalayan and Australasian realms (each $3 \%$ ), respectively.

\subsection{Epiphytes and terrestrial plants respond differently to past and present environmental factors}

Epiphytes have, on average, higher absolute standardized regression coefficients (slopes) than terrestrial plants, indicating stronger associations with environmental gradients (Figure 4). We find strong positive relationships between epiphyte richness (ER) and quotient (EQ), and tropical forest area (ER: $1.02 \pm 0.10$; EQ: $0.73 \pm 0.10$ ) and precipitation (ER: $1.10 \pm 0.10$; EQ: $0.89 \pm 0.10$ ), and a weaker, positive association with epiphyte richness and temperature (ER: $0.28 \pm 0.13$ ). Ice cover during the LGM also proves to be an important driver of epiphyte richness, revealing a negative relationship (ER: $-0.26 \pm 0.09$, Figure $4 a$ ). In comparison to epiphytes, terrestrial plants show stronger positive relationships with geographical variables, such as area and elevation, the latter of which is also positively associated with epiphytic pteridophyte richness (Figure 4c). We also note a surprising result of precipitation seasonality, which is very weakly negatively associated with terrestrial but not epiphytic plant species richness (Figure 4). The combination of environmental predictors, including biogeographical realm, explains a high degree of variance in both the global epiphyte (92\%) and terrestrial richness models (79\%), and to a lesser extent the total epiphyte quotient model (87\%).

Regardless of taxonomic group, all significant environmental variables have greater effects on epiphyte richness than on terrestrial plant richness, particularly with respect to tropical forest area for seed plants (E slope: $1.39 \pm 0.15$; $T$ slope: $0.20 \pm 0.05, p \leq .01$ ) and precipitation for pteridophytes ( $E$ slope: $1.01 \pm 0.11$; $T$ slope: $0.48 \pm 0.06, p \leq .01$ ). Despite this, our combined predictors explain a high degree of variance 




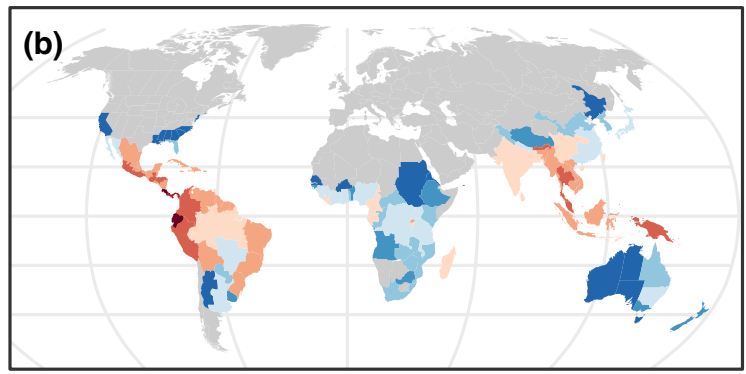

Orchidaceae

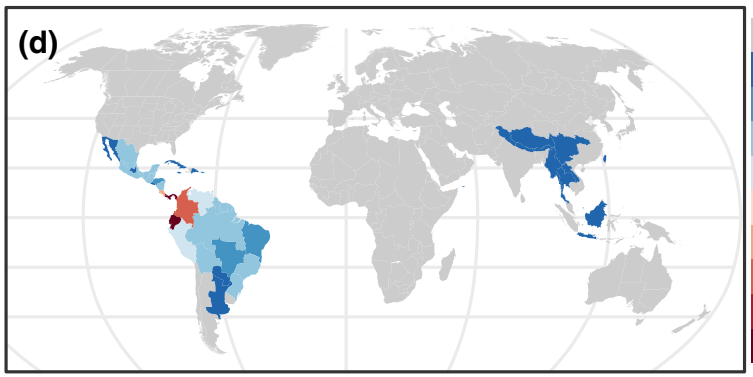

Araceae

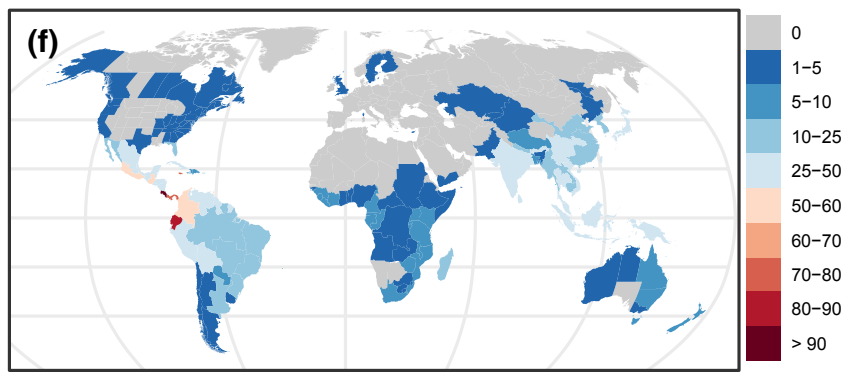

Polypodiaceae

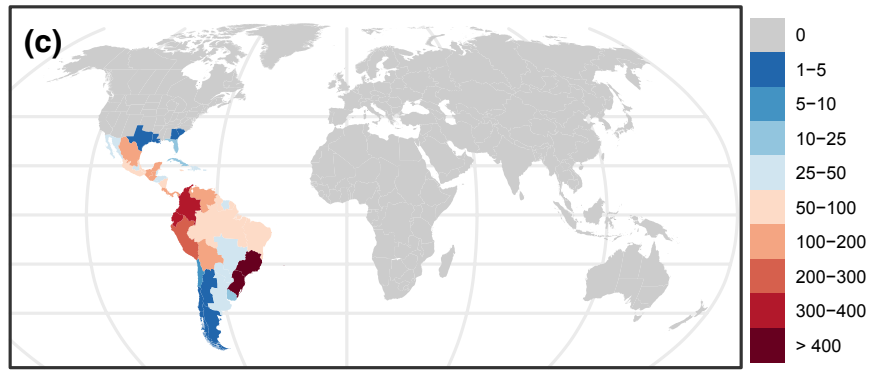

Bromeliaceae

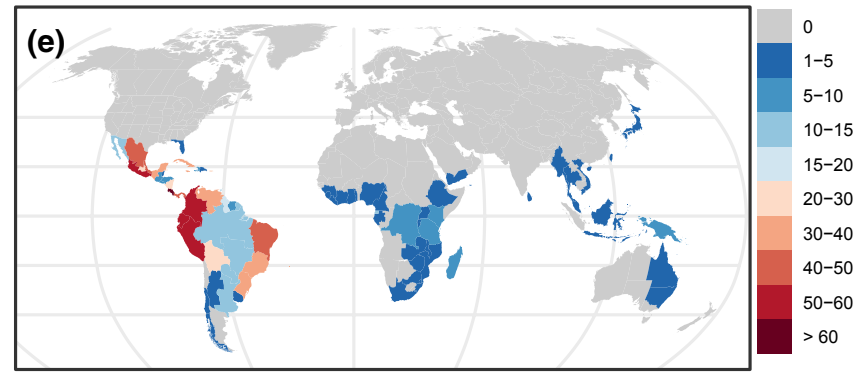

Piperaceae

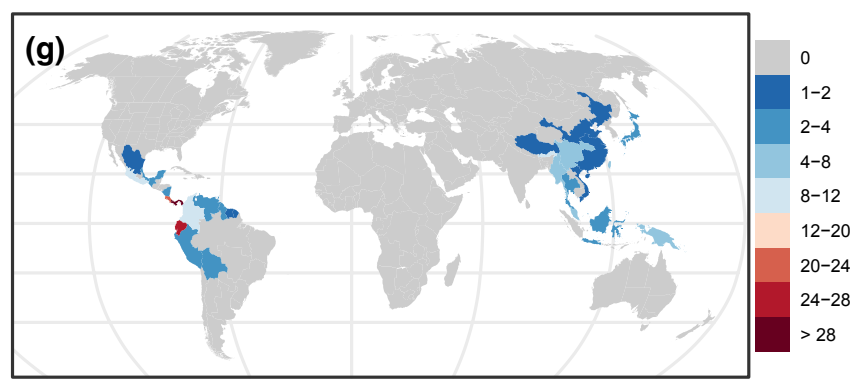

Ericaceae

FIGURE 1 Global patterns of area-corrected epiphyte species richness per $10,000 \mathrm{~km}^{2}$, (a) for all vascular epiphytes and for six of the most species-rich epiphyte families; (b) Orchidaceae, (c) Bromeliaceae, (d) Araceae, (e) Piperaceae, (f) Polypodiaceae and (g) Ericaceae 

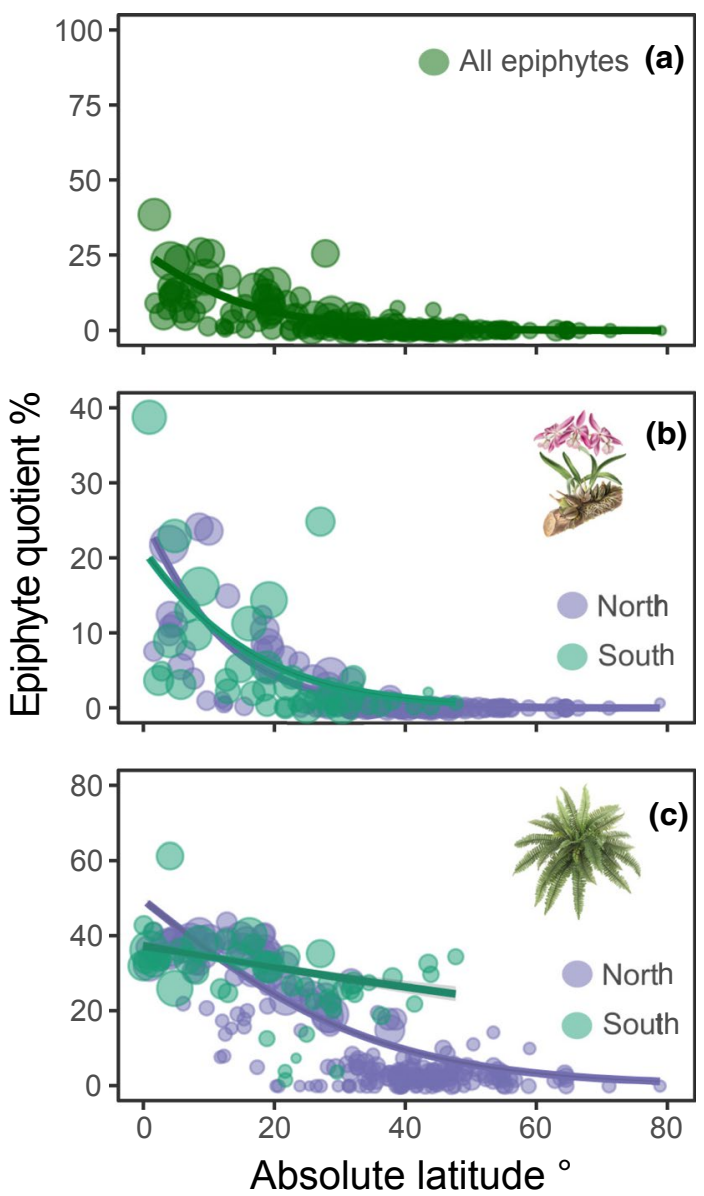

FIGURE 2 Latitudinal gradients of (a) all epiphytes and asymmetries for epiphyte quotients \% of (b) seed plants and (c) pteridophytes between the Northern (purple) and Southern Hemispheres (green). Points indicate regions weighted by species richness, with larger points indicating higher species richness. Lines indicate the strength of the relationship, including $95 \%$ confidence intervals

in both the epiphyte and terrestrial models for seed plants (variance explained epiphytes: 92\%; terrestrial plants: 78\%) and pteridophytes (epiphytes: $86 \%$; terrestrial plants: $78 \%$ ). When considering the epiphyte quotient of different taxonomic groups separately, tropical forest area has the greatest positive effect on seed plants (EQ: $1.08 \pm 0.14$, $p \leq .01$ ), and precipitation on pteridophytes (EQ: $0.55 \pm 0.07, p \leq .01$ ). The combined predictors explain a high degree of variance in both the epiphytic seed (87\%) and pteridophyte quotient models (66\%). Finally, upon inspection of the global epiphyte model residuals, we found no pattern related to absolute latitude (Supporting Information Figure S4), suggesting that the strong latitudinal decrease in epiphyte richness is well explained by the environmental predictors included.

\section{4 | DISCUSSION}

Our results reveal that epiphytes, which account for $10 \%$ of the world's vascular flora, can comprise up to $39 \%$ of the flora of large botanical regions (e.g., Ecuador), and are highly diverse in all global centres of plant diversity, barring the Mediterranean biome (see Barthlott et al., 2007 for comparison). We also find compelling evidence that epiphytes play an important role in driving the global latitudinal diversity gradient for plants, revealing three times faster decrease in species richness with increasing absolute latitude in comparison to terrestrial species.

Tropical forest area and precipitation emerge as key drivers of the latitudinal gradient in epiphyte diversity, illustrating the importance of tropical forests as habitat for epiphytes. Tropical montane cloud forests are particularly important ecosystems for epiphytes due to their high levels of atmospheric humidity (as clouds or fog) and mild temperatures, allowing for increased water interception and, therefore, a reduction in drought stress (Gotsch et al., 2016; Karger et al., 2021). Although we do not fully capture the distribution of tropical montane cloud forest in this coarse-grained analysis, we can draw comparisons with studies along elevational gradients, which often attribute the high diversity of epiphytes at mid-elevations to the presence and conditions of tropical montane cloud forests (Acebey et al., 2017; Ding et al., 2016). Indeed, regions in our study with expansive cloud forests (e.g., Ecuador, Colombia, New Guinea), also have the highest numbers of epiphytes, while regions that have fewer mountainous areas (e.g., Africa) have depauperate epiphyte floras.

Many epiphyte lineages are thought to have evolved under the dark, humid conditions of ancient tropical forests (Schimper, 1888; Schneider et al., 2004) and possess morphological and physiological traits that reflect this (e.g., relating to capturing and storing water). These functional strategies, together with the rapid decrease in epiphyte diversity with decreasing temperatures, precipitation, tropical forest area, and increasing levels of historical ice cover during the LGM, suggest that these epiphyte lineages have not deviated from their ancestral niche (niche conservatism, Wiens et al., 2010), and have not developed physiological tolerances to withstand cooler, or drier conditions (but see Kolanowska et al., 2017). The pronounced hemispherical asymmetries in epiphyte diversity, where epiphytes decrease in species numbers more rapidly in the Northern relative to the Southern Hemisphere further support the niche conservatism hypothesis (Dawson, 1986; Gentry \& Dodson, 1987; Madison, 1977; Zotz, 2005). South-temperate forests vary considerably from their northern counterparts, being mainly composed of evergreen species and growing in comparatively mild, oceanic climates (Markgraf et al., 1995; McGlone et al., 2016). These temperate rain forests (e.g., conifer-broadleaf forest in New Zealand, Valdivian temperate forest in Chile, Argentina) are often likened to having a similar multi-tiered structure as tropical forests (Dawson \& Sneddon, 1969; McGlone et al., 2016), and may explain the higher diversity of epiphytes in southern Australia, New Zealand, Argentina, and Chile, compared to equivalent latitudes in the north.

Consistent with the 'odd man out' argument (Couvreur, 2015), we find the Afrotropics to be the least diverse tropical realm, however, only when not controlling for environmental variation among regions, in which case the Afrotropics does not differ in 


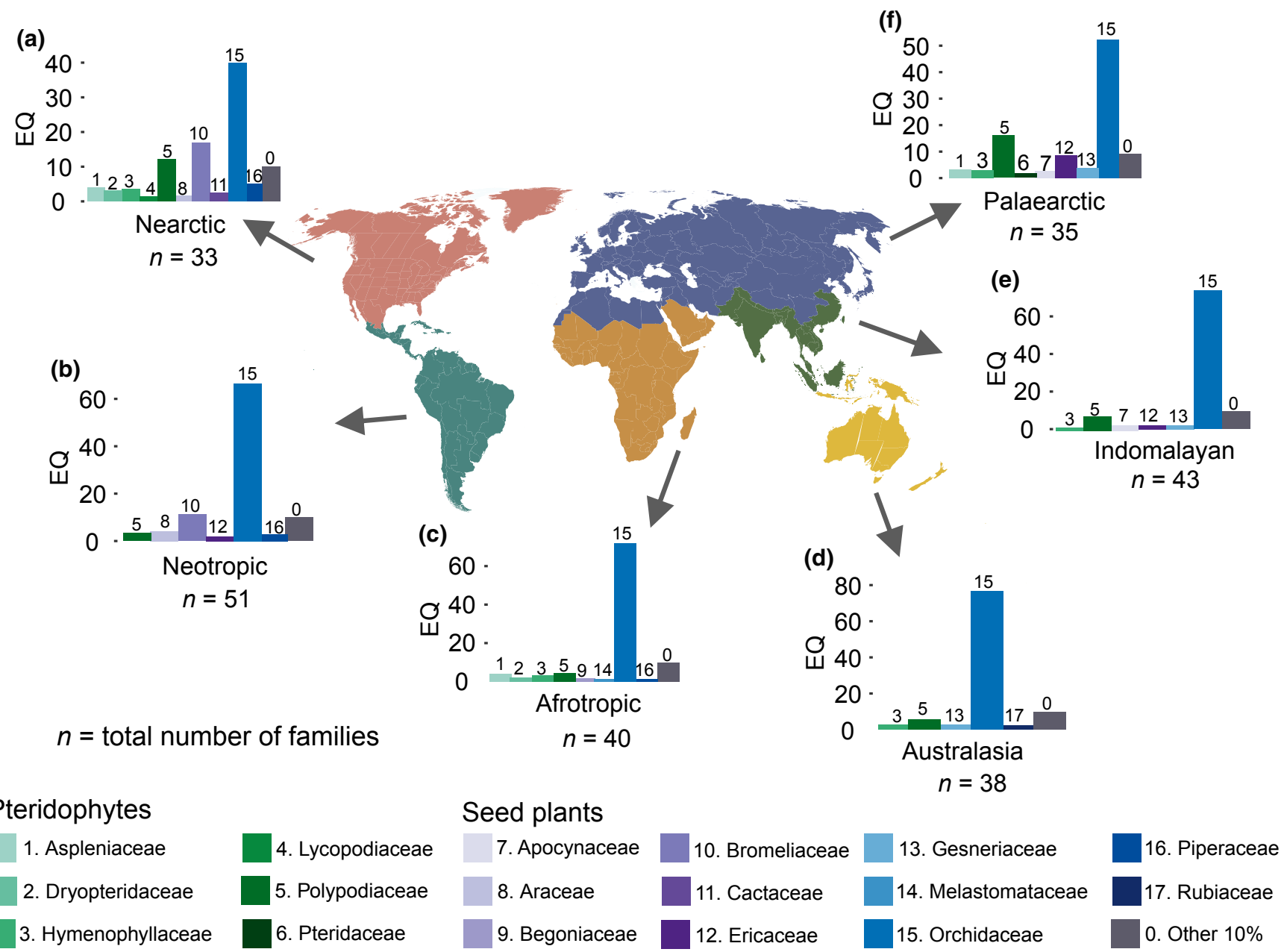

Families representing $90 \%$ of total epiphyte richness per biogeographical realm

FIGURE 3 Epiphyte quotient \% (EQ) of major families (representing 90\% of total epiphyte richness) among different biogeographical realms. Biogeographical realms are defined following Olson et al. (2001). Numbers above each column correspond to families (e.g., $15=$ Orchidaceae). Numbers below the names of biogeographical realms indicates the number of families present in that realm

epiphyte species numbers from the Indomalayan and Australasian realms. Despite this, the Afrotropics has a notable absence of epiphytic taxa in many large, cosmopolitan angiosperm families. For example, we record no epiphytic species from the Ericaceae, only one epiphytic Araceae, and only a fraction of orchids compared to the Neotropic and Indomalayan realms, most of which occur in Madagascar. This paucity can probably be explained by the greater retraction of tropical forest biomes in Africa compared to all other tropical realms during the mid-Miocene and Pleistocene (Couvreur, 2015; Kissling et al., 2012), which led to widespread species extinctions (Carlucci et al., 2017) and a reduction in habitat for epiphytes. The high diversity and endemism of orchids in Madagascar (83\% endemic, Taylor et al., 2019, 2021), however, are undoubtedly driven by the island's unique evolutionary history, including over 80 million years of isolation and subsequent radiations, particularly within the epiphytic Angraecinae subtribe and Bulbophyllum genus (Farminhão et al., 2021). Despite Madagascar having a rich epiphyte flora compared to the Afrotropical realm as a whole, its exclusion from models did not alter our results.

In contrast to the poorer epiphyte diversity observed in the Afrotropics, the Neotropical realm has over three times the number of epiphytic species of the second most diverse Indomalayan realm, with Orchidaceae (comprising $67 \%$ of the epiphytic flora), Bromeliaceae (11\%) and Araceae (4\%) being the dominant plant families. Outside of the Neotropics, however, the contribution of families to the epiphytic flora of each biogeographical realm is more heterogeneous. For example, after the three most diverse families Orchidaceae (cosmopolitan), Polypodiaceae (cosmopolitan) and Bromeliaceae (Americas), Ericaceae is the next most prominent family in the Palaearctic (8\%), Piperaceae in the Nearctic (5\%), Aspleniaceae in the Afrotropics (4\%), and Apocynaceae and Gesneriaceae in the Indomalayan and Australasian realms (each $3 \%)$, respectively. Thus, our study also demonstrates how epiphyte 


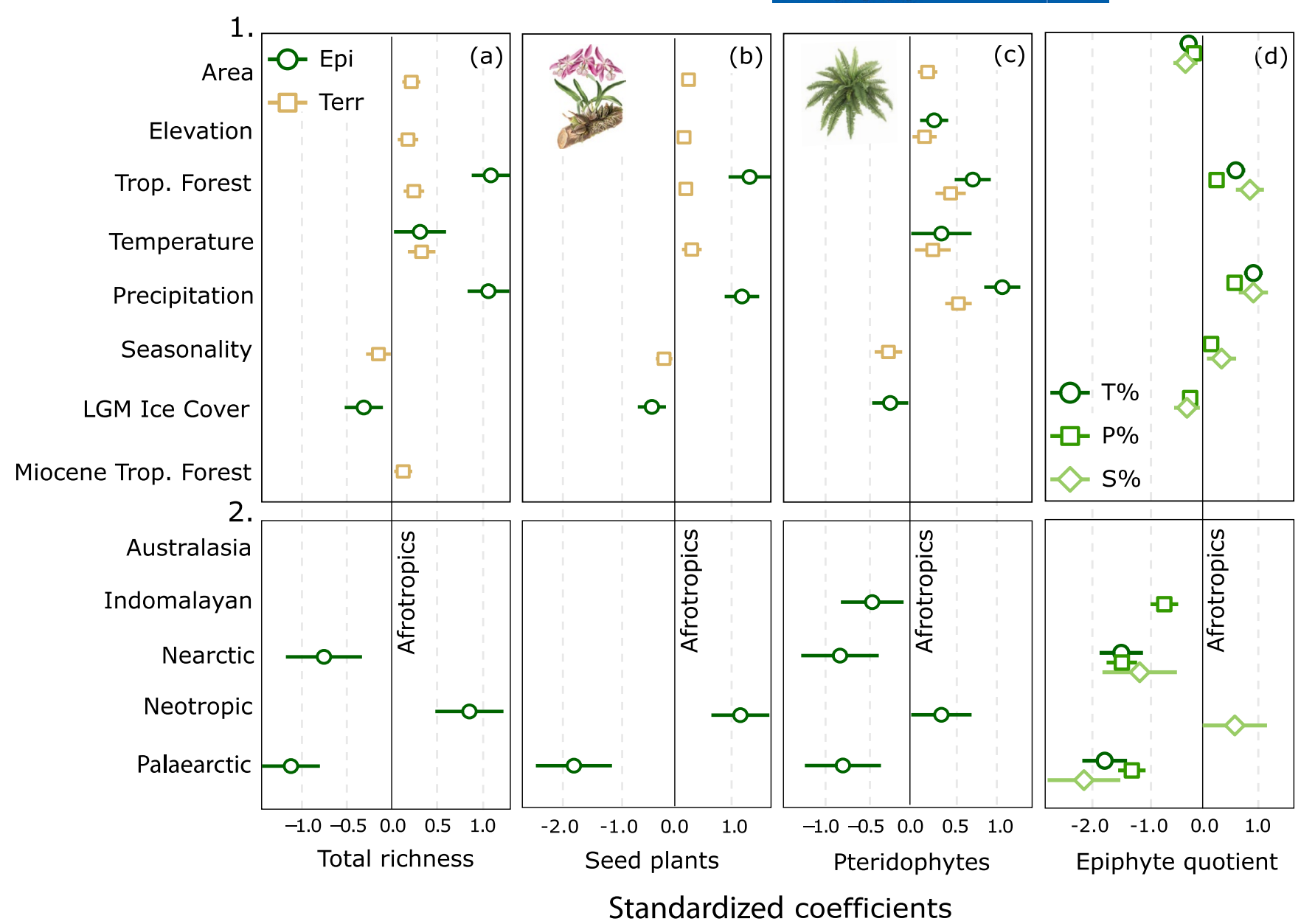

FIGURE 4 Standardized coefficient plots showing the effect of region area (Area, $\mathrm{km}^{2}$ ), elevational range (Elevation, $\mathrm{m}$ ), tropical forest area (Trop. Forest, $\mathrm{km}^{2}$ ), mean minimum monthly temperature (Temperature, ${ }^{\circ} \mathrm{C}$ ), mean annual precipitation (Precipitation, $\mathrm{mm}$ ), precipitation seasonality (Seasonality, coefficient of variation of Precipitation), ice cover during the last glacial maximum (LGM Ice Cover, $\mathrm{km}^{2}$ ), and tropical forest area during the Mid-Miocene Thermal Optimum (Miocene Trop. Forest, $\mathrm{km}^{2}$ ) on the total number of (a) epiphyte and terrestrial species, and separately for (b) seed plants, and (c) pteridophytes in row 1. Only significant predictors are shown. Epiphyte coefficients are indicated with dark green circles and terrestrial plants with gold squares. Panel (d) illustrates the effect of the same set of predictors on the epiphyte quotient \% of the total number of epiphytes ( $\mathrm{T} \%$, dark green circles), pteridophyte epiphytes (P \%, green squares) and seed plant epiphytes (S \%, light open diamonds). Confidence intervals (95\%) are also shown. The predicted values of epiphyte richness and quotient \% per biogeographical realm can be found in row 2, where 'Afrotropics' is the reference realm (i.e., $0=$ Afrotropics)

floras in different biogeographical realms are composed of different families and higher taxa revealing an important signature of biogeographical history.

Supporting the hypothesis that epiphytes are more strongly coupled to atmospheric conditions, we show that epiphytes generally display stronger relationships with climatic variables than terrestrial plants. One possible reason for this is the niche partitioning of epiphytes to within-tree microclimatic gradients, by which epiphytes display a remarkable functional variety among different taxonomic groups (Benzing, 2004). For instance, at least $14 \%$ of epiphytic pteridophytes (Hymenophyllaceae, Zotz, Weigelt et al., 2021) are poikilohydric and due to their inability to control water-loss are generally confined to humid forests (Proctor, 2012), or the lower trunks of host trees (Zotz \& Büche, 2000, but see Krömer \& Kessler, 2006). This might explain the stronger, positive effect of precipitation on epiphytic compared to terrestrial pteridophytes given that water, which is a scarce resource in many tree canopies, is a requirement for pteridophyte reproduction (Proctor, 2007). Similarly, the stronger effect of precipitation, minimum temperature and tropical forest area on epiphytic seed plants might reflect the differences in traits associated with an epiphytic compared to terrestrial life-form. For example, most terrestrial orchids can be classified as geophytes, and therefore have traits (e.g., tubers) that aid survival in highly seasonal environments (e.g., Mediterranean or temperate climates, Taylor et al., 2021), while epiphytic orchids have traits more associated with capturing and storing water within the canopy. Thus, terrestrial plants are more heavily constrained by soil conditions, which may confound the signal of macroclimate variables to some degree. Indeed, the coarse-grained nature of our analysis inevitably leads to an under-estimation of the importance of regional variation such as over elevational gradients. 
In summary, our study quantifies the substantial contribution of epiphytes-a generally neglected group of plants-to global centres of plant diversity, highlighting an important role of tropical forest biomes and historical biogeography. However, many questions still remain. Why, for example, is epiphytism so unevenly distributed among plant families? And how does this interact with historical biogeography in determining modern richness gradients? What are the key vegetative and reproductive traits that promote epiphytism in epiphyte-rich families? How does diversification in epiphytic lineages vary in space and time? Our study makes a step in this direction by providing a first quantitative baseline and by illustrating that epiphytes show remarkable differences in diversity patterns compared to terrestrial plants on a global scale and across different taxonomic groups.

\section{ACKNOWLEDGMENTS}

We sincerely thank Renske Onstein, Wolf Eiserhardt and one anonymous reviewer for helpful feedback that substantially improved our manuscript. AT received support from the German Research Foundation (Deutsche Forschungsgemeinschaft, DFG project number 447332176). HK acknowledges funding by the German Research Foundation in the framework of the DynaCom project. CK acknowledges support from the German Science Foundation (DFG, grant no. ZU 361-1/1). DK acknowledges funding from the Swiss Federal Research Institute for Forest, Snow and Landscape Research internal grant exCHELSA, ClimEx, the Joint BiodivERsA COFUND Call on 'Biodiversity and Climate Change' (project 'FeedBaCks') with the national funder Swiss National Foundation (20BD21_193907), the ERA-NET BiodivERsA-Belmont Forum with the national funder Swiss National Foundation (20BD21_184131) (part of the 2018 Joint call BiodivERsA-Belmont Forum call; project 'FutureWeb'), and the Swiss Data Science Projects SPEEDMIND and COMECO.

\section{AUTHOR CONTRIBUTIONS}

AT, GZ, HK, PW conceptualized the study, GZ assembled the epiphyte database, HK, PW and CK assembled the GIFT database, AT assembled missing species distributions, AT and PW cleaned data, LC provided tropical forest biome data, DK provided additional climate data, AT performed all analyses and drafted the manuscript. All authors contributed substantially to revisions.

\section{DATA AVAILABILITY STATEMENT}

All data accompanying the manuscript can be found as a Dryad depository (https://doi.org/10.5061/dryad.kwh70rz46). All data references are included in Supporting Information Appendix S1.

\section{ORCID}

Amanda Taylor (iD https://orcid.org/0000-0002-0420-2203

Gerhard Zotz iD https://orcid.org/0000-0002-6823-2268

Patrick Weigelt iD https://orcid.org/0000-0002-2485-3708

Lirong Cai iD https://orcid.org/0000-0001-9432-2024

Dirk Nikolaus Karger iD https://orcid.org/0000-0001-7770-6229

Christian König iD https://orcid.org/0000-0003-0585-5983
Holger Kreft iD https://orcid.org/0000-0003-4471-8236

\section{REFERENCES}

Acebey, A. R., Krömer, T., \& Kessler, M. (2017). Species richness and vertical distribution of ferns and lycophytes along an elevational gradient in Los Tuxtlas, Veracruz, Mexico. Flora, 235, 83-91. https://doi. org/10.1016/j.flora.2017.08.003

Barthlott, W., Hostert, A., Kier, G., Küper, W., Kreft, H., Mutke, J., Rafiqpoor, M. D., \& Sommer, J. H. (2007). Geographic patterns of vascular plant diversity at continental to global scales. Erdkunde, 61, 305-315. https://doi.org/10.3112/erdkunde.2007.04.01

Barton, K. (2020). MuMIn: Multi-model inference. R package version 1.43.17. https://cran.r-project.org/web/packages/MuMIn/index. html

Bates, D., Maechler, M., Bolker, B., \& Walker, S. (2015). Fitting linear mixed-effects models using Ime4. Journal of Statistical Software, 67, $1-48$.

Benzing, D. H. (1987). Vascular epiphytism: Taxonomic participation and adaptive diversity. Annals of the Missouri Botanical Garden, 74, 183204. https://doi.org/10.2307/2399394

Benzing, D. H. (1989). The evolution of epiphytism. In U. Lüttge (Ed.), Vascular plants as epiphytes (Vol. 76, pp. 15-41). Springer.

Benzing, D. H. (1990). Vascular epiphytes. General biology and related biota. Cambridge University Press.

Benzing, D. H. (1998). Vulnerabilities of tropical forests to climate change: The significance of resident epiphytes. Climate Change, 39, 519-540.

Benzing, D. H. (2004). Vascular epiphytes. In M. D. Lowman \& H. B. Rinker (Eds.), Forest canopies (pp. 175-211). Elsevier Academic Press.

Bivand, R. S., \& Wong, D. W. S. (2018). Comparing implementations of global and local indicators of spatial association. Test, 27, 716-748. https://doi.org/10.1007/s11749-018-0599-x

Brummit, R. K. (2001). World Geographical Scheme for Recording Plant Distributions, Edition 2. Biodiversity Information Standards (TDWG). http://www.tdwg.org/standards/109

Burnham, K. P., \& Anderson, D. R. (2004). Multimodel inference: understanding AIC and BIC in model selection. Sociological methods \& research, 33, 261-304.

Burns, K. C. (2010). How arboreal are epiphytes? A null model for Benzing's classifications. New Zealand Journal of Botany, 48, 185191. https://doi.org/10.1080/0028825X.2010.503775

Carlucci, M. B., Seger, G. D. S., Sheil, D., Amaral, I. L., Chuyong, G. B., Ferreira, L. V., Galatti, U., Hurtado, J., Kenfack, D., Leal, D. C., Lewis, S. L., Lovett, J. C., Marshall, A. R., Martin, E., Mugerwa, B., Munishi, P., Oliveira, Á. C. A., Razafimahaimodison, J. C., Rovero, F., ... Duarte, L. D. S. (2017). Phylogenetic composition and structure of tree communities shed light on historical processes influencing tropical rainforest diversity. Ecography, 40, 521-530. https://doi. org/10.1111/ecog.02104

Couvreur, T. L. P. (2015). Odd man out: Why are there fewer plant species in African rain forests? Plant Systematics and Evolution, 301, 12991313. https://doi.org/10.1007/s00606-014-1180-z

Danielson, J., \& Gesch, D. B. (2011). Global multi-resolution terrain elevation data 2010 (GMTED2010). U.S. Geological Survey Open-File Report 2011-1073, 26 pp.

Dawson, J. W. (1986). The vines, epiphytes and parasites of New Zealand forests. Tuatara, 28, 43-70.

Dawson, J. W., \& Sneddon, B. (1969). The New Zealand rain forest: A comparison with tropical rain forest. Pacific Science, 23, 131-147.

Díaz, I. A., Sieving, K. E., Peña-Foxon, M. E., Larraín, J., \& Armesto, J. J. (2010). Epiphyte diversity and biomass loads of canopy emergent trees in Chilean temperate rain forests: A neglected functional 
component. Forest Ecology and Management, 259, 1490-1501. https://doi.org/10.1016/j.foreco.2010.01.025

Dinerstein, E., Olson, D., Joshi, A., Vynne, C., Burgess, N. D., Wikramanayake, E., Hahn, N., Palminteri, S., Hedao, P., Noss, R., Hansen, M., Locke, H., Ellis, E. C., Jones, B., Barber, C. V., Hayes, R., Kormos, C., Martin, V., Crist, E., ... Saleem, M. (2017). An ecoregionbased approach to protecting half the terrestrial realm. BioScience, 67, 534-545. https://doi.org/10.1093/biosci/bix014

Ding, Y., Liu, G., Zang, R., Zhang, J., Lu, X., \& Huang, J. (2016). Distribution of vascular epiphytes along a tropical elevational gradient: Disentangling abiotic and biotic determinants. Scientific Reports, 6 , 19706. https://doi.org/10.1038/srep19706

Dormann, C. F., Elith, J., Bacher, S., Buchmann, C., Carl, G., Carré, G., Marquéz, J. R. G., Gruber, B., Lafourcade, B., Leitão, P. J., Münkemüller, T., McClean, C., Osborne, P. E., Reineking, B., Schröder, B., Skidmore, A. K., Zurell, D., \& Lautenbach, S. (2013). Collinearity: A review of methods to deal with it and a simulation study evaluating their performance. Ecography, 36, 27-46. https:// doi.org/10.1111/j.1600-0587.2012.07348.x

Dormann, C., McPherson, J., Araújo, M., Bivand, R., Bolliger, J., Carl, G. Davies, R., Hirzel, A., Jetz, W., Kissling, D., Kühn, I., Ohlemüller, R., Peres-Neto, P., Reineking, B., Schröder, B., Schurr, F., \& Wilson, R. (2007). Methods to account for spatial autocorrelation in the analysis of species distributional data: A review. Ecography, 30, 609-628. https://doi.org/10.1111/j.2007.0906-7590.05171.x

Ehlers, J., P. L. Gibbard, \& Hughes, P. D. (Eds.). (2011). Quaternary glaciations-Extent and chronology: A closer look. Elsevier.

Einzmann, H. J., Weichgrebe, L., \& Zotz, G. (2021). Long-term community dynamics in vascular epiphytes on Annona glabra along the shoreline of Barro Colorado Island, Panama. Journal of Ecology, 109, 1931-1946.

Farminhão, J. N. M., Verlynde, S., Kaymak, E., Droissart, V., SimoDroissart, M., Collobert, G., Martos, F., \& Stévart, T. (2021). Rapid radiation of angraecoids (Orchidaceae, Angraecinae) in tropical Africa characterised by multiple karyotypic shifts under major environmental instability. Molecular Phylogenetics and Evolution, 159, 107105. https://doi.org/10.1016/j.ympev.2021.107105

Gamisch, A., Winter, K., Fischer, G. A., \& Comes, H. P. (2021). Evolution of crassulacean acid metabolism (CAM) as an escape from ecological niche conservatism in Malagasy Bulbophyllum (Orchidaceae). New Phytologist, 231, 1236-1248.

Gentry, A. H., \& Dodson, C. H. (1987). Diversity and biogeography of Neotropical vascular epiphytes. Annals of the Missouri Botanical Garden, 74, 205-233. https://doi.org/10.2307/2399395

Gerstner, K., Dormann, C. F., Václavík, T., Kreft, H., \& Seppelt, R. (2014). Accounting for geographical variation in species-area relationships improves the prediction of plant species richness at the global scale. Journal of Biogeography, 41, 261-273. https://doi.org/10.1111/ jbi.12213

Givnish, T. J., Barfuss, M. H. J., van Ee, B., Riina, R., Schulte, K., Horres, R., Gonsiska, P. A., Jabaily, R. S., Crayn, D. M., Smith, J. A. C., Winter, K., Brown, G. K., Evans, T. M., Holst, B. K., Luther, H., Till, W., Zizka, G., Berry, P. E., \& Sytsma, K. J. (2011). Phylogeny, adaptive radiation, and historical biogeography in Bromeliaceae: Insights from an eight-locus plastid phylogeny. American Journal of Botany, 98, 872895. https://doi.org/10.3732/ajb.1000059

Givnish, T. J., Spalink, D., Ames, M., Lyon, S. P., Hunter, S. J., Zuluaga, A., Iles, W. J. D., Clements, M. A., Arroyo, M. T. K., Leebens-Mack, J., Endara, L., Kriebel, R., Neubig, K. M., Whitten, W. M., Williams, N. H., \& Cameron, K. M. (2015). Orchid phylogenomics and multiple drivers of their extraordinary diversification. Proceedings of the Royal Society B: Biological Sciences, 28, 20151553.

Göbel, C. Y., Schlumpberger, B. O., \& Zotz, G. (2020). What is a pseudobulb? Toward a quantitative definition. International Journal of Plant Sciences, 181, 686-696. https://doi.org/10.1086/709295
Gotsch, S. G., Nadkarni, N., \& Amici, A. (2016). The functional roles of epiphytes and arboreal soils in tropical montane cloud forests. Journal of Tropical Ecology, 32, 455-468. https://doi.org/10.1017/S0266 $46741600033 \mathrm{X}$

Hassler, M. (2021). World Ferns. Synonymic checklist and distribution of ferns and lycophytes of the world. www.worldplants.de/ferns/

Henrot, A.-J., François, L., Favre, E., Butzin, M., Ouberdous, M., \& Munhoven, G. (2010). Effects of $\mathrm{CO}_{2}$, continental distribution, topography and vegetation changes on the climate at the Middle Miocene: A model study. Climate of the Past, 6, 675-694.

Hernández-Rojas, A. C., Kluge, J., Noben, S., Reyes Chávez, J. D., Krömer, T., Carvajal-Hernández, C. I., Salazar, L., \& Kessler, M. (2021). Phylogenetic diversity of ferns reveals different patterns of niche conservatism and habitat filtering between epiphytic and terrestrial assemblages. Frontiers of Biogeography, 13, e50023. https://doi. org/10.21425/F5FBG50023

Hosokawa, T. (1950). Epiphyte-quotient. Botanical Magazine Tokyo, 63, 18-19. https://doi.org/10.15281/jplantres1887.63.18

Karger, D. N., Conrad, O., Böhner, J., Kawohl, T., Kreft, H., Soria-Auza, R. W., Zimmermann, N. E., Linder, H. P., \& Kessler, M. (2017). Climatologies at high resolution for the earth's land surface areas. Scientific Data, 4, 170122. https://doi.org/10.1038/sdata.2017.122

Karger, D. N., Kessler, M., Lehnert, M., \& Jetz, W. (2021). Limited protection and ongoing loss of tropical cloud forest biodiversity and ecosystems worldwide. Nature Ecology \& Evolution, 5, 854-862. https:// doi.org/10.1038/s41559-021-01450-y

Kelly, D. L., O'Donovan, G., Feehan, J., Murphy, S., Drangeid, S. O., \& Marcano-Berti, L. (2004). The epiphyte communities of a montane rain forest in the Andes of Venezuela: Patterns in the distribution of the flora. Journal of Tropical Ecology, 20, 643-666. https://doi. org/10.1017/S0266467404001671

Kier, G., Mutke, J., Dinerstein, E., Ricketts, T. H., Küper, W., Kreft, H., \& Barthlott, W. (2005). Global patterns of plant diversity and floristic knowledge. Journal of Biogeography, 32, 1107-1116. https://doi. org/10.1111/j.1365-2699.2005.01272.x

Kissling, W. D., Eiserhardt, W. L., Baker, W. J., Borchsenius, F., Couvreur, T. L. P., Balslev, H., \& Svenning, J.-C. (2012). Cenozoic imprints on the phylogenetic structure of palm species assemblages worldwide. Proceedings of the National Academy of Sciences USA, 109, 73797384. https://doi.org/10.1073/pnas.1120467109

Kolanowska, M., Grochocka, E., \& Konowalik, K. (2017). Phylogenetic climatic niche conservatism and evolution of climatic suitability in Neotropical Angraecinae (Vandeae, Orchidaceae) and their closest African relatives. PeerJ, 5, e3328

Kreft, H., \& Jetz, W. (2007). Global patterns and determinants of vascular plant diversity. Proceedings of the National Academy of Sciences USA, 104, 5925-5930. https://doi.org/10.1073/pnas.0608361104

Kreft, H., Jetz, W., Jens, M., \& Barthlott, W. (2010). Contrasting environmental and regional effects on global pteridophyte and seed plant diversity. Ecography, 33, 408-419. https://doi. org/10.1111/j.1600-0587.2010.06434.x

Kreft, H., Köster, N., Küper, W., Nieder, J., \& Barthlott, W. (2004). Diversity and biogeography of vascular epiphytes in Western Amazonia, Yasuní, Ecuador. Journal of Biogeography, 31, 1463-1476. https://doi.org/10.1111/j.1365-2699.2004.01083.x

Krömer, T., \& Kessler, M. (2006). Filmy ferns (Hymenophyllaceae) as highcanopy epiphytes. Ecotropica, 12, 57-63.

Krömer, T., Kessler, M., Gradstein, S. R., \& Acebey, A. (2005). Diversity patterns of vascular epiphytes along an elevational gradient in the Andes. Journal of Biogeography, 32, 1799-1809. https://doi. org/10.1111/j.1365-2699.2005.01318.x

Long, J. (2019). jtools: Analysis and presentation of scientific data. R package v 2.0.1. https://cran.r-project.org/web/packages/jtools/index.html

Madison, M. (1977). Vascular epiphytes: Their systematic occurrence and salient features. Selbyana, 2, 1-13. 
Markgraf, V., McGlone, M., \& Hope, G. (1995). Neogene paleoenvironmental and paleoclimatic change in southern temperate ecosystems-a southern perspective. Trends in Ecology and Evolution, 10, 143-147. https://doi.org/10.1016/S0169-5347(00)89023-0

McGlone, M. S., Buitenwerf, R., \& Richardson, S. J. (2016). The formation of the oceanic temperate forests of New Zealand. New Zealand Journal of Botany, 54, 128-155. https://doi.org/10.1080/00288 25X.2016.1158196

Méndez-Castro, F. E., Bader, M. Y., Mendieta-Leiva, G., \& Rao, D. (2018). Islands in the trees: A biogeographic exploration of epiphytedwelling spiders. Journal of Biogeography, 45, 2262-2271. https:// doi.org/10.1111/jbi.13422

Mendieta-Leiva, G., Porada, P., \& Bader, M. Y. (2020). Interactions of epiphytes with precipitation partitioning. In I. T. van Stan, E. Gutmann, \& J. Friesen (Eds.), Precipitation partitioning by vegetation (pp. 133146). Springer International Publishing.

Nadkarni, N. M., Schaefer, D., Matelson, T. J., \& Solano, R. (2004). Biomass and nutrient pools of canopy and terrestrial components in a primary and a secondary montane cloud forest, Costa Rica. Forest Ecology and Management, 198, 223-236. https://doi.org/10.1016/j. foreco.2004.04.011

Nervo, M. H., da Silva Coelho, F. V., Windisch, P. G., \& Overbeck, G. E. (2016). Fern and lycophyte communities at contrasting altitudes in Brazil's subtropical Atlantic Rain Forest. Folia Geobotanica, 51, 305 317. https://doi.org/10.1007/s12224-016-9253-0

Olson, D. M., Dinerstein, E., Wikramanayake, E. D., Burgess, N. D., Powell, G. V. N., Underwood, E. C., D'amico, J. A., Itoua, I., Strand, H. E., Morrison, J. C., Loucks, C. J., Allnutt, T. F., Ricketts, T. H., Kura, Y., Lamoreux, J. F., Wettengel, W. W., Hedao, P., \& Kassem, K. R. (2001). Terrestrial ecoregions of the world: A new map of life on earth. BioScience, 51, 933-938.

Pridgeon, A. M. (1987). The velamen and exodermis of orchid roots. Orchid Biology: Reviews and Perspectives, 4, 141-192.

Proctor, M. C. F. (2007). Ferns, evolution, scale and intellectual impedimenta. New Phytologist, 176, 504-506. https://doi. org/10.1111/j.1469-8137.2007.02232.x

Proctor, M. C. F. (2012). Light and desiccation responses of some Hymenophyllaceae (filmy ferns) from Trinidad, Venezuela and New Zealand: Poikilohydry in a light-limited but low evaporation ecological niche. Annals of Botany, 109, 1019-1026. https://doi.org/10.1093/aob/mcs012

$R$ Core Team. (2020). R: A language and environment for statistical computing. R Foundation for Statistical Computing.

Ray, N., \& Adams, J. (2001). A GIS-based vegetation map of the world at the last glacial maximum (25,000-15,000 BP). Internet Archaeology, 11, 1-44. https://doi.org/10.11141/ia.11.2

Schimper, A. F. W. (1888). Die epiphytische Vegetation Amerikas. G. Fischer.

Schimper, A. F. W., Balfour, I. B., Fisher, W. R., \& Groom, P. (1903). Plantgeography upon a physiological basis. Clarendon Press.

Schneider, H., Schuettpelz, E., Pryer, K. M., Cranfill, R., Magallón, S., \& Lupia, R. (2004). Ferns diversified in the shadow of angiosperms. Nature, 428, 553-557. https://doi.org/10.1038/nature02361

Schuettpelz, E., \& Pryer, K. M. (2009). Evidence for a Cenozoic radiation of ferns in an angiosperm-dominated canopy. Proceedings of the National Academy of Sciences USA, 106, 11200-11205. https://doi. org/10.1073/pnas.0811136106

Silvera, K., Santiago, L. S., Cushman, J. C., \& Winter, K. (2009). Crassulacean acid metabolism and epiphytism linked to adaptive radiations in the Orchidaceae. Plant Physiology, 149, 1838-1847. https://doi.org/10.1104/pp.108.132555

Stuntz, S., Ziegler, C., Simon, U., \& Zotz, G. (2002). Diversity and structure of the arthropod fauna within three canopy epiphyte species in central Panama. Journal of Tropical Ecology, 18, 161-176. https:// doi.org/10.1017/S0266467402002110

Taylor, A., Keppel, G., Weigelt, P., Zotz, G., \& Kreft, H. (2021). Functional traits are key to understanding orchid diversity on islands. Ecography, 44, 703-714. https://doi.org/10.1111/ecog.05410
Taylor, A., Weigelt, P., König, C., Zotz, G., \& Kreft, H. (2019). Island disharmony revisited using orchids as a model group. New Phytologist, 223, 597-606. https://doi.org/10.1111/nph.15776

WCSP. (2018). World Checklist of Selected Plant Families. Facilitated by the Royal Botanic Gardens, Kew. https://wcsp.science.kew.org/cite.do

Weigelt, P., König, C., \& Kreft, H. (2020). GIFT-A Global Inventory of Floras and Traits for macroecology and biogeography. Journal of Biogeography, 47, 16-43. https://doi.org/10.1111/jbi.13623

WFO. (2019). World Flora Online. http://www.worldfloraonline.org

Whittaker, R. J., Triantis, K. A., \& Ladle, R. J. (2008). A general dynamic theory of oceanic island biogeography. Journal of Biogeography, 35 , 977-994.

Wiens, J. J., Ackerly, D. D., Allen, A. P., Anacker, B. L., Buckley, L. B., Cornell, H. V., Damschen, E. I., Jonathan Davies, T., Grytnes, J.A., Harrison, S. P., Hawkins, B. A., Holt, R. D., McCain, C. M., \& Stephens, P. R. (2010). Niche conservatism as an emerging principle in ecology and conservation biology. Ecology Letters, 13, 13101324. https://doi.org/10.1111/j.1461-0248.2010.01515.x

Zotz, G. (2005). Vascular epiphytes in the temperate zones-a review. Plant Ecology, 176, 173-183. https://doi.org/10.1007/s1125 8-004-0066-5

Zotz, G. (2013). The systematic distribution of vascular epiphytes - a critical update. Botanical Journal of the Linnean Society, 171, 453-481. https://doi.org/10.1111/boj.12010

Zotz, G. (2016). Plants on plants. The biology of vascular epiphytes. Springer.

Zotz, G., Almeda, F., Bautista-Bello, A. P., Eskov, A. K., GiraldoCañas, D., Hammel, B. E., Harrison, R. D., Köster, N., Krömer, T., Lowry, P. P. II, Moran, R. C., Plunkett, G. M., \& Weichgrebe, L. (2021). Hemiepiphytes revisited. Perspectives in Plant Ecology, Evolution and Systematics, 51, 125620. https://doi.org/10.1016/j. ppees.2021.125620

Zotz, G., \& Büche, M. (2000). The epiphytic filmy ferns of a tropical lowland forest - species occurrence and habitat preferences. Ecotropica, 6, 203-206.

Zotz, G., Leja, M., Aguilar-Cruz, Y., \& Einzmann, H. J. (2020). How much water is in the tank? An allometric analysis with 205 bromeliad species. Flora, 264, 151557. https://doi.org/10.1016/j. flora.2020.151557

Zotz, G., Weigelt, P., Kessler, M., Kreft, H., \& Taylor, A. (2021). EpiList 1.0: A global checklist of vascular epiphytes. Ecology, 102, e03326.

\section{BIOSKETCH}

Amanda Taylor (lead author) is a researcher with broad interests in the fields of macroecology, conservation biology, functional ecology and island biology. Her current research focuses on explaining patterns and drivers of plant biodiversity at the global scale often using orchids as a model group.

\section{SUPPORTING INFORMATION}

Additional supporting information may be found in the online version of the article at the publisher's website.

How to cite this article: Taylor, A., Zotz G., Weigelt P., Cai L., Karger D. N., König C., \& Kreft H. (2022). Vascular epiphytes contribute disproportionately to global centres of plant diversity. Global Ecology and Biogeography, 31, 62-74. https:// doi.org/10.1111/geb.13411 